\title{
A study of the dental health of patients undergoing heart valve surgery
}

\author{
Simon N. Rogers
}

Department of Oral Surgery, Freeman Hospital, Freeman Road, High Heaton, Newcastle upon Tyne NE7 7DN, $U K$.

\begin{abstract}
Summary: The mouth is a possible source of infection in patients receiving prosthetic heart valves. In this study, the dental health of such patients was found to be very poor. Whilst most of the patients were asymptomatic, only two were dentally fit and $65 \%$ required the extraction of one or more teeth. On average, patients had not attended a dental practice for more than 9 years.

This level of dental neglect, in a group of patients particularly at risk, is alarming and this study indicates that a higher standard of oral care is still required and that a lack of symptoms does not indicate dental fitness.
\end{abstract}

\section{Introduction}

Patients undergoing prosthetic heart valve surgery are at high risk of developing infective endocarditis in the peroperative and postoperative periods. ${ }^{\prime}$ This is the first reported study to analyse prospectively the dental health of patients referred prior to or after valvular surgery.

\section{Patients, methods and results}

Thirty one patients entered the study. All were referred from the cardiology unit for a dental opinion over a one year period from August 1985 to July 1986. All patients had significantly diseased heart valves and were seen either prior to or after prosthetic valve surgery. Full medical and dental histories were taken and the presence and severity of dental disease recorded.

There were 15 males and 16 females, their ages ranged from 26 to 68 years (mean 51.4). Fourteen patients had a clear history of rheumatic fever. Twenty three patients were seen before surgery, 15 having mitral, 6 aortic and 2 combined valvular disease. For 14 patients the operation date was recorded, a mean of 4.1 days after dental assessment.

Of those 8 patients who were seen postoperatively, 6 had mitral, one aortic and one both mitral and aortic prosthetic valves placed. Three patients were seen shortly after surgery (mean 6.3 days) whilst the other 5

Correspondence: S.N. Rogers B.D.S., F.D.S.R.C.S., The Lawns, School Lane, Alvechurch, Birmingham B48 7SD, UK (currently Medical Student, University of Birmingham). Accepted: 2 March 1989 had had surgery on average 10.2 years previously. These late referrals are included as they remain at high risk of developing endocarditis.

One pre-surgery and one post-surgery patient were seen in the weeks following an episode of infective endocarditis of Streptococcus sanguis origin. Ironically both had good oral hygiene.

Twenty four $(77 \%)$ patients had no dental symptoms. Only seven $(23 \%)$ saw their dentist at least yearly and the mean time since the last attendance for the whole sample was 8 years 7 months (range 1 month to 30 years). Ten patients had dentures. Only one had full upper and lower dentures but also had three roots remaining all of which were involved in inflammatory processes.

Table I shows the result of the clinical and radiographic examination. Twenty two $(65 \%)$ patients required dental extractions, on average 5.9 teeth.

Table I Results of clinical and radiographic examination

\begin{tabular}{lc}
\hline & Number of patients \\
\hline Dentally fit & 2 \\
Good oral hygiene & 3 \\
Retained roots & 6 \\
Gross caries & 25 \\
Periapical abscess & 10 \\
Chronic periodontal bone loss & 22 \\
Periodontal abscess & 3 \\
Other pathology (i.e. oral & 4 \\
candidal infection, unerupted & \\
teeth.) & \\
\hline
\end{tabular}

(C) The Fellowship of Postgraduate Medicine, 1989 
Extractions were performed under local anaesthesia with antibiotic prophylaxis. The antibiotic regimen followed established guidelines. ${ }^{2}$ Preoperative patients received $3 \mathrm{~g}$ oral amoxycillin one hour before extractions and a further $3 \mathrm{~g}$ six hours postoperatively and if allergic to penicillin were given $1.5 \mathrm{~g}$ erythromycin stearate one hour preoperatively and $1.5 \mathrm{~g}$ six hours after treatment. Patients with pre-existing prosthetic valves were covered by intravenous amoxycillin and gentamicin.

\section{Discussion}

The level of dental health in this selective study of high risk patients was very poor, although the importance of good oral health in the prevention of bacteraemia and subsequent infective endocarditis is widely accepted. ${ }^{3-5}$ It is recognized that bacteraemia occurs during dental procedures as well as during tooth brushing and mastication. ${ }^{6}$ The incidence of bacteraemia increases in patients with gum disease who have teeth extracted, ${ }^{7}$ and the risk of endocarditis is directly related to the number of bacteria penetrating the blood stream. ${ }^{8}$ Despite these findings it can be difficult to implicate dental treatment as the cause of endocarditis as the portal of entry of the bacteria is often not apparent. ${ }^{9}$ Poor dental hygiene predisposes to the development of infective endocarditis in that the likelihood of bacteraemia is higher when the gums are inflamed and oral sepsis predisposes the patient to spontaneous bacteraemia without any intervention in the mouth. ${ }^{6}$ In patients with infected prosthetic valves there is significant mortality and morbidity as well as the necessity for intensive therapy and, in some cases, urgent surgery. Mortality rates of $50 \%$ are quoted in early postoperative endocarditis. ${ }^{10}$ It is essential that all identifiable sources of sepsis are eliminated in these patients.

In contrast to previous published work the majority of patients in this study were seen close to the time of

\section{References}

1. American Heart Association. Committee report: Prevention of infective endocarditis. Circulation 1977, 56: 139A-143A.

2. Cawson, R.A. The antibiotic prophylaxis of infective endocarditis. A summary of the BSAC working party report. Br Dent J 1983, 154: 183-184.

3. Thom, A.R. \& Howe, G.L. The dental status of cardiac patients. Br Heart J 1972, 34: 1302-1307.

4. Holbrook, W.P., Willey, R.F. \& Shaw, T.R.D. Dental health in patients susceptible to infective endocarditis. $\mathrm{Br}$ Med J 1981, 283: 371-372.

5. Shanson, D.C. In: Cawson, R.A. (ed) The Nature and Prevention of Bacterial Endocarditis. The Medicine Publishing Foundation Symposium Series 3. Medicine Education Services Limited, Oxford, 1982, p.30. surgery when their dental state should have been at its best. It is possible that some bias was introduced as these patients were considered to be in need of a dental opinion. During preparation for prosthetic valve surgery, it is standard practice to advise patients to see $\bar{c}$ their general dental practitioner. Some neglect to do $\vec{F}$ this and remain at risk of complications due to dental pathology. This observation begs the question as to듬 how active a part the hospital services should take in $\overline{\bar{N}}$ checking that patients have had any necessary treat $-\widehat{\Phi}$ ment. Lack of symptoms was no protection against the presence of a septic focus of dental origin and, unfortunately, it is well recognized that many adults $\vec{\circ}$ only seek a dental opinion when in pain. ${ }^{11}$ In this study, the level of disease in asymptomatic patients $\vec{\sigma}$ was worryingly high and must raise doubts as to the dental fitness of patients in centres where referral is on 3 the basis of symptoms alone. Edentulous patients are at risk, ${ }^{3}$ as shown by the one such patient in this study. or

As the number of patients undergoing heart valve ${ }^{\prime}$ surgery increases it becomes more important that simple measures to reduce risks are taken. Dental $\mathrm{C}^{-}$ disease should be eliminated prior to surgery and a $O$ high level of oral care maintained thereafter if the prevalence of infective endocarditis is to be reduced. $\vec{c}$ This study indicates that there is still a need for closer co-operation between physicians, surgeons, the dental $\vec{\circ}$ practitioners and the patients so that dental sepsis cain be avoided in this high risk group of patients.

\section{Acknowledgement}

I should like to thank Mr M.P. Holden for allowing me to study patients treated under his care, Miss A. Downing and? Mr K. Pizarro for their clinical assistance and Dr S.E. Fishero for help in preparing the manuscript.

6. Guntheroth, W.G. How important are dental proce- $\bigcirc$ dures as a cause of infective endocarditis? Am J Cardiol 1984, 54: 797-801.

7. Everrett, E.D. \& Hirschmann, J.V. Transient bacteremia and endocarditis prophylaxis. A review. Medicine (Bal- N timore) 1977, 56: 61-77.

8. Tzukert, A.A., Levine, E. \& Sela, M. Prevention of $\mathrm{O}$ endocarditis, not by antibiotics alone. Oral Surg Oral N Med Oral Pathol 1986, 62: 385-388.

9. Bayliss, R., Clarke, Oakley C., Somerville, W. \& Whitfield, A.G.W. The teeth and infective endocarditis. Br Heart J 1983, 50: 506-512. 
10. Rossiter, S.J., Stinson, E.B., Oyer, P.E. et al. Prosthetic valve endocarditis. Comparison of heterograft tissue valves and mechanical valves. $J$ Thorac Cardiovasc Surg 1978, 76: 795-803.
11. Todd, J.E. \& Walker, A.M. Adult Dental Health in England and Wales, 1978, Volume 1. Office of Population Censuses and Surveys. Her Majesty's Stationery Office, London, 1980. 